\title{
Neurofibromatosis during pregnancy, what about anesthesia?
}

\author{
Ayoub El Amri ${ }^{1 *}$, Fahd Elabdi ${ }^{1}$, Abdelghafour Elkoundi $^{2}$, Mohammed Amine Elhasnaoui ${ }^{1}$ \\ Author affiliations: \\ 1- Maternité Souissi Service d'anesthésie-Réanimation, Université Mohammed V, 10100 Rabat, Morocco. \\ 2- Hôspital militaire d'instruction, Service d'anesthésie Réanimation, Université Mohammed V, 10100 Rabat, Morocco. \\ *Correspondance: Ayoub El Amri, Résidence Med Sabri Imm B Appt 01 Hay Riad, Rabat, Morocco; Tel: +33666289559; E-mail: \\ ayoub.elamri01@gmail.com
}

\section{Abstract}

Neurofibromatosis type 1 is a rare neurocutaneous condition that can have widespread and deleterious effects on various organ systems, including the spine with implications for the choice of anesthetic technique.

We report the case of a parturient, who was received in the emergency room of the maternity ward of our hospital during the active phase of labor, without neuraxial imaging, in whom a cesarean section was indicated and performed under general anesthesia. Anesthesia for the parturient with neurofibromatosis is still not well documented, its management needs to be multidisciplinary, with a careful pre-conception planning.

Key words: Neurofibromatosis, imaging, neuraxial anesthesia, pregnancy.

Abbreviations: Neurofibromatosis type 1: NF-1

Citation: Amri AE, Elabdi F, Elkoundi A, Elhasnaoui MA. Neurofibromatosis during pregnancy, what about anesthesia? Anaesth. pain intensive care 2020;24(6):

Received: 3 August 2019, Reviewed: 7 May 2020, 27 May 2020

\section{Introduction}

Neurofibromatosis type 1 or von Recklinghausen's disease, described in 1882 is the most common neurofibromatosis with an incidence of one birth per three or four thousand. Autosomal dominant transmission is full penetration, but with large interfamily and intra-family phenotypic variations partly reflecting the different mutations. ${ }^{1}$ Neurofibromatosis is a disease characterized by typical skin lesions, eye lesions of variable and localized forms either in the central nervous system, the neuraxis or on the path of peripheral nerves, all of its manifestations may worsen during pregnancy, thus the choice of anesthetic technique merits careful systemic evaluation. ${ }^{1-9}$ We report the anesthetic management of a parturient received in the emergency room of the maternity ward during the active phase of labor. She was planned to be delivered by cesarean section.

\section{Case Presentation}

A 28 -year-old patient (weight $72 \mathrm{~kg}$, height $1.68 \mathrm{~m}$ ), primiparous, suffered from type 1 neurofibromatosis since her puberty but had no exacerbations of lesions during her pregnancy. The family history indicated her mother had had the same disease. She was admitted to the emergency department of the maternity ward during labor. The clinical examination at admission found a blood pressure at $110 / 60 \mathrm{mmHg}$, a heart rate at $92 \mathrm{bpm}$, without edema of the lower limbs. Obstetric examination noted the presence of uterine contractions, ruptured membranes, and an open cervix at $3 \mathrm{~cm}$ and a clinically favorable pelvis. Obstetric ultrasound revealed a singleton fetal pregnancy with positive cardiac activity and normal fetal measurements.

The vaginal route was initially opted, and the patient remained under clinical supervision and forceps delivery in the delivery room with morphine 


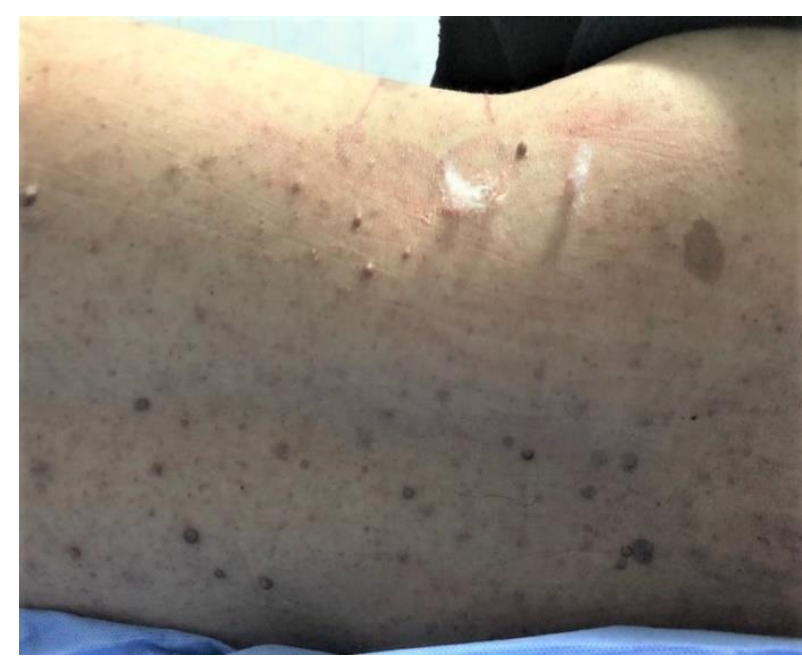

Figure 1: View of the back demonstrating multiple skin neurofibromata

analgesia. Two hours later, acute fetal distress was detected necessitating an emergency cesarean section.

The pre-anesthetic examination did not reveal any indication of a difficult intubation; Mallampati class 1 on examination of the upper airways, with good mouth opening and a thyromandibular distance $>6.5$ $\mathrm{cm}$. Objective mucocutaneous examination revealed "café au lait" spots and neurofibromas covering the whole body. Neurological examination was normal with no signs for intracranial hypertension.

In the absence of central nervous system imaging, general anesthesia was planned. Rapid sequence induction was done with inj. propofol $2 \mathrm{mg} / \mathrm{kg}$ and rocuronium $1 \mathrm{mg} / \mathrm{kg}$. Fentanyl $3 \mu \mathrm{g} / \mathrm{kg}$ was administered after fetal extraction. Endotracheal intubation was easily achieved. Anesthesia was maintained with isoflurane. Her vital signs remained stable throughout the peri-operative period. A male baby, Apgar score 10/10, and a $3.3 \mathrm{~kg}$ weight was delivered. The patient was extubated after waking up with no neurological complications detected. The postoperative outcome was simple, allowing the patient to be discharged within 5 days.

\section{Discussion}

Neurofibromatosis type 1 (NF-1) is a rare neurocutaneous condition that can have widespread and deleterious effects on various organ systems, including the spine with implications for the choice of anesthetic technique. ${ }^{2}$ Clinical presentations of neurofibromatosis and some anesthetic implications have recently been reviewed. ${ }^{5}$ Although our parturient did not show neurological signs, spinal tumors have been diagnosed in $40 \%$ of asymptomatic patients with the disease. ${ }^{5}$

In obstetrics, epidural analgesia is the most effective method of pain relief during labor, but the majority of tumors occur laterally in the intervertebral foramen, and may be traumatized directly by an epidural needle if they extend towards the midline.${ }^{5}$ Neuraxial anesthesia in these patients therefore carries an increased risk of bleeding, hematoma formation and increased intracranial pressure. Several cases of post-epidural hematoma have been described. ${ }^{3-5}$

However, neuraxial blocks can be safely performed in the absence of spinal neurofibromas on CT or MRI even in an emergency if possible. ${ }^{7-10}$

Providing effective analgesia when epidural is contraindicated in the parturient is a real challenge for the anesthesiologists. In cases similar to that described in our report, intramuscular or intravenous analgesia with opiates (meperidine) or inhaled nitrous oxide is usually considered instead. Although the use of inj. remifentanil is increasingly being popular in obstetric patients, and several studies have confirmed its effectiveness, yet its use is still under debate. $^{8}$

In our case, analgesia was initially provided by intravenous morphine. However, before obstetrical emergency and in the absence of spinal imaging, general anesthesia was the choice technique, and for postoperative analgesia we opted for inj. fentanyl.

\section{Conclusion}

Anesthesia for the parturient with neurofibromatosis is not well documented. General anesthesia is currently the technique of choice if spinal status is unknown, but other alternatives are being evaluated. Spinal imaging is recommended before any neuraxial procedure.

\section{Conflict of interest}

None declared by the authors

\section{Authors' contribution}

AEA: Care of the patient and manuscript writing FE: Care of the patient.

AGE, MAEH: Manuscript writing.

\section{References}

1. Montard R, Putz C, Barrali M, Kantelip B, Montard M. 
Neurofibromatose de type I segmentaire: à propos d'une localisation orbito-temporale. J Fr Ophtalmol. 2007 Nov;30(9):938-941. [PubMed] DOI: 10.1016/s0181-5512(07)74033-0

2. Dounas M, Mercier FJ, Lhuissier C, Benhamou D. Epidural analgesia for labour in a parturient with neurofibromatosis. Can J Anesth. $1995 \mathrm{May} ; 42(5 \mathrm{Pt}$ 1):420-422. [PubMed] DOI: $10.1007 / \mathrm{BF} 03015490$

3. Spiegel JE, Hapgood A, Hess PE. Epidural anesthesia in a parturient with neurofibromatosis type 2 undergoing cesarean section. Int J Obstet Anesth. 2005 Oct;14(4):336-339. [PubMed] DOI: 10.1016/j.jijoa.2005.04.012

4. Fisher MM. Anaesthetic diffuclties in neurofibromatosis. Anaesthesia 1975;30:648-650. [PubMed] DOI: 10.1111/j.1365-2044.1975.tb00925.x

5. Youngs $P$, Human $M$. Epidural haematoma in a parturient with neurofibromatosis. $\mathrm{Br} \mathrm{J}$ Anaesth. 2002;88(5):745. [PubMed]

6. Esler MD, Durbridge J, Kirby S. Epidural haematoma after dural puncture in a parturient with neurofibromatosis. Br J Anaesth. 2001;87:932-934. [PubMed] DOI: $10.1093 / \mathrm{bja} / 87.6 .932$

7. Thakkar SD, Feigen U, Mautner VF. Spinal tumours in neurofibromatosis type 1: an MRI study of frequency, multiplicity and variety. Neuroradiology.
1999;41:625-629. [PubMed] DOI: 10.1007/s002340050814

8. Galvan JM, Hofkamp MP. Usefulness of intrapartum magnetic resonance imaging for a parturient with neurofibromatosis type 1 during induction of labor for preeclampsia. Proc (Bayl Univ Med Cent). 2018 Jan 10;31(1):92-93. [PubMed] DOI: 10.1080/08998280.2017.1401837

9. Kranke $P$, Girard T, Lavand'homme P, Melber A, Jokinen J, Muellenbach RM, et al. Must we press on until a young mother dies? Remifentanil patient controlled analgesia in labour may not be suited as a "poor man's epidural". BMC Pregnancy Childbirth. 2013 Jul 2;13:139. [PubMed] DOI: 10.1186/14712393-13-139

10. Malinovsky JM, Hamidi A, Lelarge C, BoulayMalinovsky $C$. Anaesthetic management of patient with neurological disease: Focus on regional anaesthesia. Presse Med. 2014 Jul-Aug;43(7-8):756764. [PubMed] DOI: $10.1016 / j .1 p m .2013 .11 .028$

11. Kapur S, Kumar S, Eagland K. Anesthetic management of a parturient with neurofibromatosis 1 and Charcot-Marie-Tooth disease. J Clin Anesth. 2007 Aug;19(5):405-406. [PubMed] DOI: 10.1016/j.jclinane.2007.03.001 